Article

\title{
Carbon Mass Balance in Arthrospira platensis Culture with Medium Recycle and High $\mathrm{CO}_{2}$ Supply
}

\author{
Masatoshi Kishi ${ }^{1} * \mathbb{C}^{\mathbb{D}}$, Yukina Yamada ${ }^{1}$, Tomoyo Katayama ${ }^{2}$, Tatsushi Matsuyama ${ }^{1}$ and \\ Tatsuki Toda ${ }^{1}$ \\ 1 Faculty of Science and Engineering, Soka University, 1-236 Tangi-cho, Hachioji, Tokyo 192-8577, Japan; \\ yu-yamada@soka.gr.jp (Y.Y.); tatsushi@soka.ac.jp (T.M.); toda@soka.ac.jp (T.T.) \\ 2 Graduate School of Agricultural and Life Sciences, The University of Tokyo 1-1-1, Yayoi, Bunkyo, \\ Tokyo 113-8657, Japan; akatayam@mail.ecc.u-tokyo.ac.jp \\ * Correspondence: masa-kishi@soka.gr.jp; Tel.: +81-42-691-4086
}

Received: 29 November 2019; Accepted: 24 December 2019; Published: 27 December 2019

\section{Featured Application: Carbon capture and utilization (CCU); Pigment production; Nutraceuticals} production.

\begin{abstract}
Medium recycling combined with $\mathrm{CO}_{2}$ recovery helps sustainable use of the alkaline medium in Arthrospira culture. However, high $\mathrm{CO}_{2}$ supply may cause inorganic carbon accumulation and $\mathrm{pH}$ reduction, which could result in low $\mathrm{CO}_{2}$ recovery and reduced algal growth. This study aimed to elucidate the effect of medium recycling and high $\mathrm{CO}_{2}$ supply through carbon mass balance analysis in Arthrospira culture. In all $\mathrm{CO}_{2}$ supply conditions, carbon supply was higher than Arthrospira carbon assimilation, which accounted for $30-58 \%$ of supply. However, $\mathrm{CO}_{2}$ recovery of nearly $100 \%$ and $63 \%$ for lower $\left(0.20\right.$ and $\left.0.39 \mathrm{gC} \mathrm{L}^{-1} \mathrm{~d}^{-1}\right)$ and higher $\left(0.59 \mathrm{gC} \mathrm{L}^{-1} \mathrm{~d}^{-1}\right) \mathrm{CO}_{2}$ supply rates were achieved, respectively, because of the high concentration of the alkaline agent. The excess carbon accumulated in the medium and ultimately escaped from the system in a form of dissolved inorganic carbon (DIC). Dissolved organic carbon (DOC) contributed to $16-24 \%$ of the total photosynthetically assimilated carbon, and the final concentration reached $260-367 \mathrm{mgC} \mathrm{L}^{-1}$, but there was no significant growth reduction caused by DIC and DOC accumulation. This study demonstrated the stability of the medium-recycling process even at high $\mathrm{CO}_{2}$ supply rates although a balanced supply is recommended for longer operations.
\end{abstract}

Keywords: Arthrospira; carbon dioxide; $\mathrm{CO}_{2}$ capture and utilization; mass balance; medium recycle; $\mathrm{pH}$

\section{Introduction}

Alkaliphilic microalgae and cyanobacteria (inclusively referred to as algae here) have been of great interest in a commercial application. Their selective growth conditions (i.e., high $\mathrm{pH}$ and alkalinity) prevent overgrowth of other organisms even in outdoor open-pond cultivations and allows relatively easy quality control. Among alkaliphilic algae, Arthrospira (also known as Spirulina) is the most commercially produced genus because of its high nutritional value (protein up to $77 \% \mathrm{dwt}$, minerals, and vitamins) [1] and application for blue natural color pigment production [2]. The global production of Arthrospira has been estimated to be approximately 10,000 metric tons in a report in 2013 [2] and is still expanding. Its emerging bio-active compounds have also been well studied [3-6].

The challenge in mass-cultivation of alkaliphilic microalgae, however, is the large requirement of alkaline agents. For example, the conventional Zarrouk medium requires $16.8 \mathrm{~kg}$ of sodium bicarbonate $\left(\mathrm{NaHCO}_{3}\right)$ for every cubic meter of the medium [7]. Thus, medium recycles after biomass harvest is a preferred operation $[8,9]$. In a used medium, photosynthetic utilization of bicarbonate $\left(\mathrm{HCO}_{3}{ }^{-}\right)$and 
carbonate $\left(\mathrm{CO}_{3}{ }^{2-}\right)$ results in increased $\mathrm{pH}\left(\mathrm{OH}^{-}\right.$production), but $\mathrm{CO}_{2}$ supply regenerates $\mathrm{HCO}_{3}{ }^{-}$and $\mathrm{CO}_{3}{ }^{2-}$ back from $\mathrm{OH}^{-}$[10]. As such, medium recycling allows sustainable use of alkaline agent if combined with appropriate $\mathrm{CO}_{2}$ supply.

Due to the $\mathrm{CO}_{2}$ requirement, algae mass-cultivation is considered as a key technology for $\mathrm{CO}_{2}$ bio-capture from $\mathrm{CO}_{2}$ containing gas sources such as flue gas, steel mills, and biogas [11,12], meriting both mass-culture cost reduction and environmental impact. With the recent demands for a reduction in $\mathrm{CO}_{2}$ emission to prevent global climate change, algae are considered as one of the key organisms for $\mathrm{CO}_{2}$ capture and utilization (CCU) processes [13,14]. In these processes, captured $\mathrm{CO}_{2}$ is utilized for algal photosynthesis to produce bioproducts such as biofuel, bioplastics, and other materials [13]. Although the carbon footprint differs depending on the use of algal biomass [14], carbon utilization for microalgal biodiesel production is one of the best options compared to chemical production. Even as protein sources, algal protein production has approximately 20 times lower carbon footprint compared to beef [15]. To capture $\mathrm{CO}_{2}$ in the gas, chemical/physical absorption, membrane separation, and chemical looping techniques have been attempted [16]. The alkaline medium of Arthrospira is suitable for $\mathrm{CO}_{2}$ recovery through chemical absorption [17]. The biggest advantage is the high alkalinity that could trap $\mathrm{CO}_{2}$. For example, dissolved inorganic carbon (DIC) optimum concentration is in the range of $0.01-0.1 \mathrm{~mol} \mathrm{~L}^{-1}$ in freshwater species like Chlorella [18-20], while it is $0.1-0.4 \mathrm{~mol} \mathrm{~L}^{-1}$ for Arthrospira platensis [17]. With this high alkalinity, the alkaliphilic algal medium can absorb much more $\mathrm{CO}_{2}$ into the same amount of liquid without $\mathrm{pH}$ change due to the buffer function of DIC.

In the practical $\mathrm{CO}_{2}$ recovery process, $\mathrm{CO}_{2}$ supply and/or algal productivity may fluctuate depending on the seasons or operational variations. In such cases, $\mathrm{CO}_{2}$ carbon supply may exceed the photosynthetic carbon demand, which may interfere with $\mathrm{CO}_{2}$ recovery rate and algal growth owing to DIC accumulation and $\mathrm{pH}$ reduction. Although the alkaline media of Arthrospira has a high buffer capacity and carbon absorptivity, continued high $\mathrm{CO}_{2}$ supply may have effects. Feasibility needs to be tested through carbon absorption modeling and carbon mass balance analysis. In previous studies, optimization of culture condition [21], modeling based on separate experiments of $\mathrm{CO}_{2}$ recovery and biomass production [22], and economic and energy analysis based on calculation [23] have been reported, little information has been obtained regarding the combined process of Arthrospira medium-recycled culture with $\mathrm{CO}_{2}$ recovery. While a very recent paper described $\mathrm{CO}_{2}$ recovery with Arthrospira [24], information on carbon mass balance in such conditions is scarce, and the effects of high $\mathrm{CO}_{2}$ supply and medium recycle have not been clearly revealed. The knowledge of the destiny of $\mathrm{CO}_{2}$ in media-recycling Arthrospira culture shall support environmentally and economically improved systems. Therefore, this study aimed to elucidate the carbon mass flux in the Arthrospira platensis culture coupled with medium recycling and high $\mathrm{CO}_{2}$ supply.

\section{Materials and Methods}

\subsection{Algal Strain, Growth Medium, and Inoculum Preparation}

Arthrospira platensis NIES-39 was used in this experiment. The algal strain was cultured with modified SOT medium [25] containing (mg L $\left.{ }^{-1}\right): \mathrm{NaHCO}_{3}, 22,680 ; \mathrm{K}_{2} \mathrm{HPO}_{4}, 500 ; \mathrm{NaNO}_{3}, 2,500$; $\mathrm{Na}_{2} \mathrm{SO}_{4}, 815 ; \mathrm{NaCl}, 1,000 ; \mathrm{MgSO}_{4} \cdot 7 \mathrm{H}_{2} \mathrm{O}, 200 ; \mathrm{CaCl}_{2}, 30 ; \mathrm{FeSO}_{4} \cdot 7 \mathrm{H}_{2} \mathrm{O}, 10 ; \mathrm{Na}_{2}$ EDTA, 72; $\mathrm{H}_{3} \mathrm{BO}_{3}$, 2.86; $\mathrm{MnSO}_{4} \cdot 7 \mathrm{H}_{2} \mathrm{O}, 2.5 ; \mathrm{ZnSO}_{4} \cdot 7 \mathrm{H}_{2} \mathrm{O}, 0.222 ; \mathrm{CuSO}_{4} \cdot 5 \mathrm{H}_{2} \mathrm{O}, 0.079 ; \mathrm{Na}_{2} \mathrm{MoO}_{4} \cdot 2 \mathrm{H}_{2} \mathrm{O}, 0.021$. The DIC concentration in the modified medium was $0.27 \mathrm{~mol} \mathrm{~L}^{-1}$. The medium $\mathrm{pH}$ was adjusted to 10.5 by addition of $0.215 \mathrm{~mol} \mathrm{~L}^{-1} \mathrm{NaOH}$.

For the preparation of inoculum, A. platensis was grown in an Erlenmeyer flask filled with autoclaved SOT medium. To avoid precipitation during autoclave sterilization, the medium was separated into two batches; the first consists of $\mathrm{NaHCO}_{3}$ and $\mathrm{K}_{2} \mathrm{HPO}_{4}$ and the second of the others. Both batches were autoclaved at $121{ }^{\circ} \mathrm{C}$ for $20 \mathrm{~min}$ and mixed after cooling down to room temperature. The medium was stirred with a magnetic stirrer continuously at $350 \mathrm{rpm}$ to avoid flocculation of cell 
colonies. Cool-white fluorescent light at $150 \mu \mathrm{mol}$ photons $\mathrm{m}^{-2} \mathrm{~s}^{-1}$ was continuously irradiated. Algal cells at a late log-growth phase were used as inoculum for the experiment. In the medium-recycling during Arthrospira semi-continuous culture, the medium was filter-sterilized with a $0.22-\mu \mathrm{m}$ membrane filter (Millipore, USA) instead of autoclaving.

\subsection{Experimental Design and Culture Conditions}

A semi-continuous experiment was conducted using a set of two reactors: an absorption column and a photobioreactor (PBR) (Figure 1). Three different $\mathrm{CO}_{2}$ supply rates, 0.20, 0.39, and $0.59 \mathrm{gC}$ L-PBR ${ }^{-1} \mathrm{~d}^{-1}$ (Runs 1-3; Table 1), were tested based on a previous $A$. platensis $\mathrm{CO}_{2}$ fixation rate of $0.39 \mathrm{gC} \mathrm{L}^{-1} \mathrm{~d}^{-1}$ into account [17]. $\mathrm{CO}_{2}$ was injected by the headspace replacement instead of bubbling for controlling $\mathrm{CO}_{2}$ supply rates and prolongation of gas-liquid equilibration time.

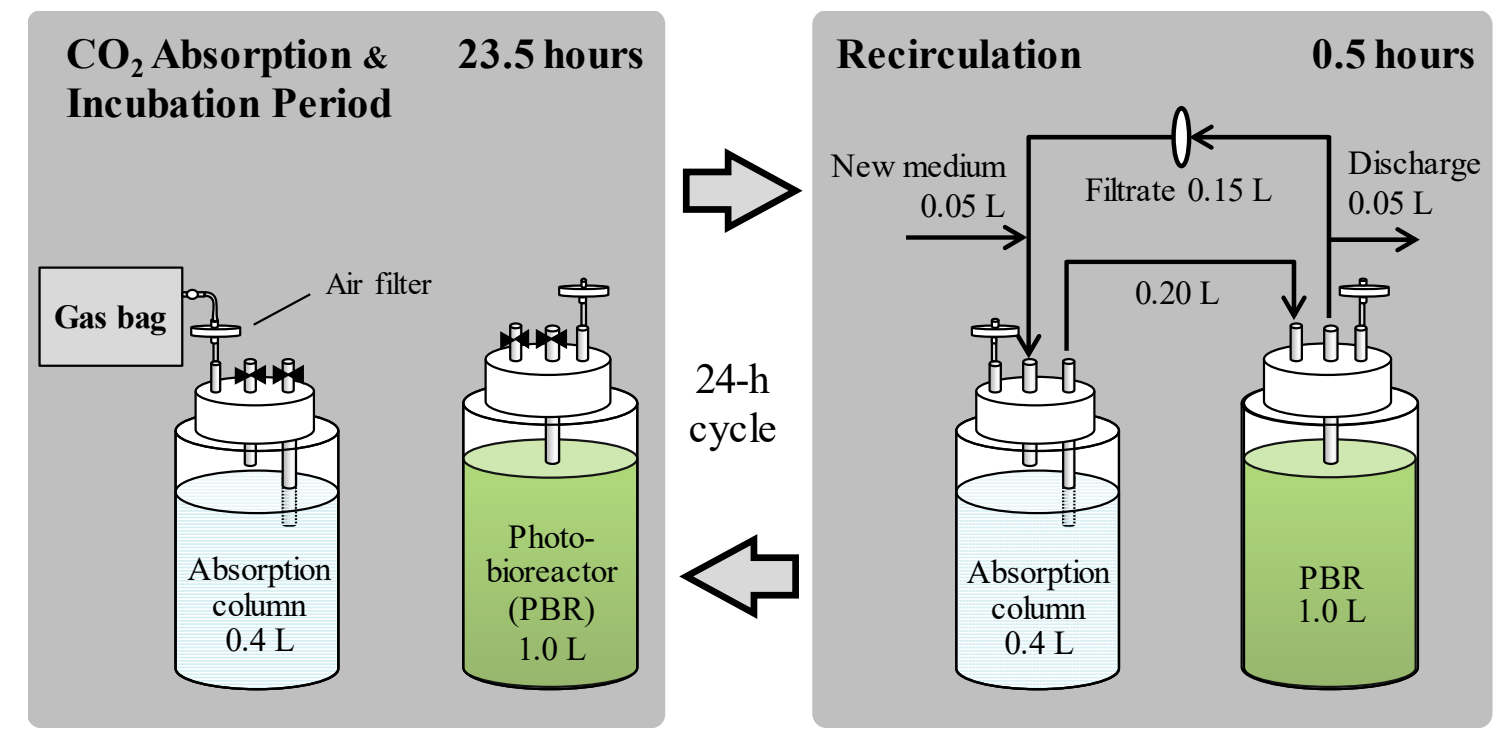

Figure 1. Experimental set-up of the semi-continuous two-phase $\mathrm{CO}_{2}$ recovery process. After 23.5 hours of $\mathrm{CO}_{2}$ absorption and algal incubation period, the medium was partially recirculated between the two reactors. After recirculation, the headspace of the absorption column was replaced with $\mathrm{CO}_{2}$ containing gas (Table 1) and a newly filled gas bag was attached.

Table 1. Gas supply configuration for $\mathrm{CO}_{2}$ absorption column.

\begin{tabular}{|c|c|c|c|c|c|c|}
\hline \multirow{2}{*}{ Run } & \multicolumn{2}{|c|}{$\mathrm{CO}_{2}$ Supply Rate } & \multirow{2}{*}{$\begin{array}{c}\text { Headspace } \\
\text { (L) }\end{array}$} & \multirow{2}{*}{$\begin{array}{c}\text { Headspace } \mathrm{CO}_{2} \\
(\%)\end{array}$} & \multirow{2}{*}{$\begin{array}{c}\mathrm{CO}_{2} \text { in Gasbag } \\
\text { (L) }\end{array}$} & \multirow{2}{*}{$\begin{array}{c}N_{2} \text { in Gasbag }{ }^{a} \\
\text { (L) }\end{array}$} \\
\hline & $\left(\mathrm{gC} \mathrm{L}^{\left.-\mathrm{PBR}^{-1} \mathrm{~d}^{-1}\right)}\right.$ & $\left(g C L-A^{\prime} s^{-1} d^{-1}\right)$ & & & & \\
\hline 1 & 0.20 & 0.49 & 0.73 & 55 & 0 & 0.40 \\
\hline 2 & 0.39 & 0.98 & 0.72 & 100 & 0.07 & 0.74 \\
\hline 3 & 0.59 & 1.5 & 0.74 & 100 & 0.45 & 0.75 \\
\hline
\end{tabular}

a Nitrogen was prepared to maintain the headspace at the atmospheric level. PBR: Photobioreactor. Abs: $\mathrm{CO}_{2}$ absorption column.

The absorption column was a 1-L glass medium bottle with an active volume of $0.4 \mathrm{~L}$ and a gas-liquid interfacial area of approximately $73 \mathrm{~cm}^{2}$. For the start-up of the experiment, the autoclaved column was filled with a 0.4-L filter-sterilized medium. The headspace of the absorption column was replaced with different concentrations of $\mathrm{CO}_{2} / \mathrm{N}_{2}$ mixture for each $\mathrm{CO}_{2}$ supply rates (Table 1 ). Nitrogen gas of the volume same as that of headspace was injected to all the gasbags so that the headspace pressure remained at the atmospheric pressure $\left(1.013 \times 10^{5} \mathrm{~Pa}\right)$ even after all $\mathrm{CO}_{2}$ was absorbed. The absorption columns were placed in an incubator at $25^{\circ} \mathrm{C}$ under dark, and the absorbent was stirred continuously with magnetic stirrers approximately at $200 \mathrm{rpm}$. 
The PBR was a glass column reactor with an active volume of $1 \mathrm{~L}$ and an inner diameter of $106 \mathrm{~mm}$. The PBR was semi-open with 0.2- $\mu \mathrm{m}$ air-filter (Aervent-50, Millipore, USA) attached on top to aseptically alleviate pressure build-up due to oxygen production. The PBR was incubated at $35^{\circ} \mathrm{C}$ with 24-hour continuous light with the surface photosynthetic photon flux density (PPFD) of $300 \mu \mathrm{mol}$ photons $\mathrm{m}^{-2} \mathrm{~s}^{-1}$.

\subsection{Experimental Procedures}

Twenty-four hours after $\mathrm{CO}_{2}$ injection into the absorption column and inoculation of PBR, algal harvest and medium recycle was operated (Figure 1). Firstly, $0.2 \mathrm{~L}$ of the algal suspension was withdrawn from the PBR, out of which, $0.05 \mathrm{~L}$ was discharged as analytical sample and $0.15 \mathrm{~L}$ was filtered through multiple screen meshes and a glass fiber filter with pore size of $0.7 \mu \mathrm{m}(\mathrm{GF} / \mathrm{F}$, Whatman, USA) to obtain filtrate for later transfer into the absorption column. Secondly, $0.2 \mathrm{~L}$ of the solution in the absorption column was transferred to the PBR aseptically. Finally, $0.15 \mathrm{~L}$ of the filtrate was mixed with 0.05-L new modified SOT medium, filtered through a sterile $0.22-\mu \mathrm{m}$ membrane filter (Millipore Express ${ }^{\circledR}$ PLUS, Millipore, San Diego, CA, USA), and aseptically transferred to the absorption column to complete the liquid recycle.

The headspace of the absorption column was then replaced by blowing the respective concentrations of $\mathrm{CO}_{2}$ gas at $1 \mathrm{~L} \mathrm{~min}^{-1}$ for $3 \mathrm{~min}$, and a refilled gas bag was attached. The same procedure was repeated every 24 hours. Samples were taken from the algal suspension and the $\mathrm{CO}_{2}$ absorbent both before and after the media recycle. The hydraulic retention times (HRT) of the absorption column, the PBR, and the entire system were 1.8, 4.75, and 18 days, respectively. The experiment was continued for 18 days.

\subsection{Analytical Procedures}

The algal suspension was used to measure algal dry weight (DW) and algal cell carbon and nitrogen content. The filtrate of algal suspension was used to measure $\mathrm{pH}$, electrical conductivity, nutrients (nitrate, nitrite, and phosphorus), dissolved inorganic carbon (DIC), and dissolved organic carbon (DOC). The gas sample was used to measure headspace $\mathrm{CO}_{2}, \mathrm{~N}_{2}$, and $\mathrm{O}_{2}$ concentration. The amount of $\mathrm{CO}_{2}$ absorbed into the medium was calculated from the difference of DIC concentration before and after the 24-h absorption period.

Algal DW was measured every day using glass fiber filters. Firstly, algal suspensions were filtered through pre-weighed glass fiber filters with a pore size of $0.7 \mu \mathrm{m}(\mathrm{GF} / \mathrm{F}$, Whatman, USA) and washed with distilled water three times. Then, filters were dried in an oven at $60^{\circ} \mathrm{C}$ for over 24 hours and subsequently cooled to room temperature in a desiccator before weighing. Filters were weighed with an ultra-micro balance (XP6U Ultra Micro Comparator, Mettler Toledo, Columbus, OH, USA). Algal cell carbon and nitrogen contents were measured by measuring particulate organic carbon and nitrogen (POC and PON) of filters samples using an elemental analyzer (Flash $2000 \mathrm{CHN}$, Thermo, Waltham, MA, USA). To measure DIC and DOC, TOC analyzer (TOC- $\mathrm{V}_{\mathrm{CSH}}$, Shimadzu, Kyoto, Japan) was used. Nutrients (nitrate, nitrite, and phosphate) were analyzed with an automated nutrient analyzer (SWAAN, BL-TEC, Tokyo, Japan).

Gas composition $\left(\mathrm{CO}_{2}, \mathrm{~N}_{2}\right.$, and $\left.\mathrm{O}_{2}\right)$ was measured using a gas chromatograph (Shimadzu, GC-2014, Japan) equipped with a packed column (Shincarbon ST, $6.0 \mathrm{~m}$ long, $3 \mathrm{~mm}$ I.D., Shimadzu, Japan) and a thermal conductivity detector. The temperature of the injector and the detector were maintained at $120^{\circ} \mathrm{C}$ and $260{ }^{\circ} \mathrm{C}$, respectively. The column temperature was gradually increased from $40^{\circ} \mathrm{C}$ to $250^{\circ} \mathrm{C}$. Helium was used as the carrier gas with a flow rate of $40 \mathrm{~mL} \mathrm{~min}^{-1}$. 


\subsection{Calculations and Statistical Analysis}

\subsubsection{Modeling $\mathrm{pH}$ Variation with DIC Change}

The composition of DIC was calculated based on the following equations [26]:

$$
\begin{gathered}
{\left[\mathrm{CO}_{2}\right]=\frac{D I C}{1+\frac{K_{1}}{\left[\mathrm{H}^{+}\right]}+\frac{K_{1} K_{2}}{\left[\mathrm{H}^{+}\right]^{2}}}} \\
{\left[\mathrm{HCO}_{3}^{-}\right]=\frac{D I C}{1+\frac{\left[\mathrm{H}^{+}\right]}{K_{1}}+\frac{K_{2}}{\left[\mathrm{H}^{+}\right]}}} \\
{\left[\mathrm{CO}_{3}^{2-}\right]=\frac{D I C}{1+\frac{\left[\mathrm{H}^{+}\right]}{K_{2}}+\frac{\left[\mathrm{H}^{+}\right]^{2}}{K_{1} K_{2}}}}
\end{gathered}
$$

where $K_{1}$ and $K_{2}$ are stoichiometric constants for bicarbonate and carbonate, respectively. In this study, $\mathrm{p} K_{1}=6.38$ [27] and $\mathrm{p} K_{2}=9.8$ were assumed. The $\mathrm{p} K_{2}$ value was derived from $\mathrm{NaOH}$ titration (cf. Supplementary material Section S1).

Based on the above equations, $\mathrm{pH}$ variation with $\mathrm{CO}_{2}$ absorption/desorption was modeled. The buffering function of phosphate and borate was assumed to be negligible because their concentrations were about 100 times lower than the DIC concentration. In the current experiment, DIC concentration can be expressed as:

$$
D I C=\left[\mathrm{CO}_{2}\right]+\left[\mathrm{HCO}_{3}^{-}\right]+\left[\mathrm{CO}_{3}^{2-}\right]=c_{0}+\Delta D I C
$$

where $c_{0}$ is the initial DIC concentration by the addition of $\mathrm{NaHCO}_{3}\left(0.27 \mathrm{~mol} \mathrm{~L}^{-1}\right)$, and $\triangle D I C$ is the change in DIC concentration due to $\mathrm{CO}_{2}$ absorption or photosynthetic assimilation ( $\mathrm{mol} \mathrm{L}^{-1}$ ). Charge balance in the medium can be expressed as:

$$
\left[\mathrm{H}^{+}\right]+\left[\mathrm{Na}^{+}\right]=\left[\mathrm{H}^{+}\right]+c_{0}+c_{b}=\left[\mathrm{OH}^{-}\right]+\left[\mathrm{HCO}_{3}^{-}\right]+2\left[\mathrm{CO}_{3}^{2-}\right]
$$

where $c_{b}$ is the final concentration of $\mathrm{NaOH}$ in the modified SOT medium that raised $\mathrm{pH}$ to 10.5 $\left(0.215 \mathrm{~mol} \mathrm{~L}^{-1}\right)$. Using the ion product constant of water $\left(K_{w}=\left[\mathrm{H}^{+}\right]\left[\mathrm{OH}^{-}\right]=1.0 \times 10^{-14} \mathrm{~mol}^{2} \mathrm{~L}^{-2}\right)$, Equation (12) can be expressed as:

$$
\left[\mathrm{H}^{+}\right]+c_{0}+c_{b}=\frac{\mathrm{K}_{\mathrm{w}}}{\left[\mathrm{H}^{+}\right]}+\left[\mathrm{HCO}_{3}^{-}\right]+2\left[\mathrm{CO}_{3}^{2-}\right]
$$

Finally, Equations (6), (10), (11) and (13) can be formulated into a quartic equation:

$$
\begin{array}{r}
{\left[\mathrm{H}^{+}\right]^{4}+\left(K_{1}+c_{0}+c_{b}\right)\left[\mathrm{H}^{+}\right]^{3}+\left(K_{1} K_{2}+K_{1} c_{b}-K_{w}-K_{1} \Delta D I C\right)\left[\mathrm{H}^{+}\right]^{2}} \\
+K_{1}\left(K_{2} c_{b}-K_{w}-K_{2} c_{0}-2 K_{2} \Delta D I C\right)\left[\mathrm{H}^{+}\right]-K_{1} K_{2} K_{w}=0
\end{array}
$$

In the current experiment, all variables in Equation (7) except for $\triangle D I C$ and $\left[\mathrm{H}^{+}\right]$remained constant. Therefore, $\mathrm{pH}$ variation with $\mathrm{CO}_{2}$ absorption/desorption can be estimated based on changes in DIC concentration $(\triangle D I C)$ with this model. The quartic equation was solved with Mathematica 8.0 (Wolfram Research, Champaign, IL, USA).

Buffer intensity, $\beta$, was calculated based on the following approximation for diprotic acids [28]:

$$
\beta=-\frac{d \mathrm{C}_{\mathrm{A}}}{d \mathrm{pH}} \cong 2.3\left(\left[\mathrm{H}^{+}\right]+\left[\mathrm{OH}^{-}\right]+\frac{\left[\mathrm{CO}_{2}\right]\left[\mathrm{HCO}_{3}^{-}\right]}{\left[\mathrm{CO}_{2}\right]+\left[\mathrm{HCO}_{3}^{-}\right]}+\frac{\left[\mathrm{HCO}_{3}^{-}\right]\left[\mathrm{CO}_{3}^{2-}\right]}{\left[\mathrm{HCO}_{3}^{-}\right]+\left[\mathrm{CO}_{3}^{2-}\right]}\right)
$$


where $d \mathrm{C}_{\mathrm{A}}$ is the infinitesimal amount of acids required to decrease $d \mathrm{pH}$. The equilibrated $\mathrm{CO}_{2}$ gas concentration was calculated according to Henry's law:

$$
p_{\mathrm{CO}_{2}}=\left[\mathrm{CO}_{2}\right] \times \frac{1}{H^{c p}}
$$

where $p_{\mathrm{CO}_{2}}$ is the partial pressure of $\mathrm{CO}_{2}$ under equilibrium condition $(\mathrm{Pa}),\left[\mathrm{CO}_{2}\right]$ is the aqueous concentration of $\mathrm{CO}_{2}\left(\mathrm{~mol} \mathrm{~L}^{-1}\right)$, and $H^{c p}$ is Henry's law solubility constant $\left(3.30 \times 10^{-7} \mathrm{~mol} \mathrm{~L}^{-1} \mathrm{~Pa}^{-1}\right)$ (Sander 2015).

\subsubsection{Biomass Production, Carbon Fixation, and Carbon Mass Balance}

Algal volumetric production rate $\left(P_{x} ; \mathrm{gDW} \mathrm{L} \mathrm{L}^{-1} \mathrm{~d}^{-1}\right)$ was calculated with the following equation:

$$
P_{x}=\frac{x_{2}-x_{1}}{t_{2}-t_{1}}
$$

where $x_{i}$ is biomass concentration $\left(\mathrm{gDW} \mathrm{L}^{-1}\right)$ at time $t_{i}(\mathrm{~d})$. The growth steady-state was defined as a period with less than $10 \%$ variation in the 3-day moving averages of DW, which was Day 10-18 for all Runs in this study.

The carbon mass balance was calculated using the following equations:

$$
\begin{gathered}
C_{i n}=\sum_{i=1}^{18} C_{2 i n^{i}} \\
C_{o u t}=(D I C+D O C)_{A B S f}-(D I C+D O C)_{A B S_{0}}+ \\
(P O C+D I C+D O C)_{P B R f}-(P O C+D I C+D O C)_{P B R_{0}}+ \\
\sum_{i=1}^{18}(D I C+D O C)_{A B S s^{i}}+\sum_{i=1}^{18}(P O C+D I C+D O C)_{P B R s^{i}}-\sum_{i=1}^{18}(D I C+D O C)_{N^{i}}
\end{gathered}
$$

where $C_{\text {in }}$ and $C_{\text {out }}$ represent the total incoming and outgoing carbon $(\mathrm{gC})$ after 18 days of the experiment, respectively. $C_{2 i n}$ refers to the carbon dioxide supplied to the process. $A B S_{0}$ and $P B R_{0}$ refer to the carbon mass in the initial medium of the $\mathrm{CO}_{2}$ absorption column and PBR, respectively. $A B S f$ and $P B R f$ indicate the final carbon mass of each reactor. $A B S s$ and $P B R s$ represent the carbon mass in each sample taken every day. $N$ represents carbon mass in the new SOT medium.

\subsubsection{Statistical Analysis}

Results are expressed as means \pm standard deviations, where available. The correlation coefficient was obtained using simple regression analysis (Excel software). Results from different conditions were analyzed using the Tukey-Kramer method. Differences with $p<0.05$ were considered significant.

\section{Results}

\subsection{Change in $\mathrm{pH}$ and DIC Concentration with $\mathrm{CO}_{2}$ Absorption}

The $\mathrm{pH}$ in both absorption columns and PBRs repeated reduction and elevation every 24 hours upon the medium circulation and $\mathrm{CO}_{2}$ gas replenishment (Figure 2), but the range was smaller in PBRs than in absorption columns. Most of the supplied $\mathrm{CO}_{2}$ was absorbed in Runs 1 and 2, while the removal efficiency in Run 3 was 63\% (Table 2). 

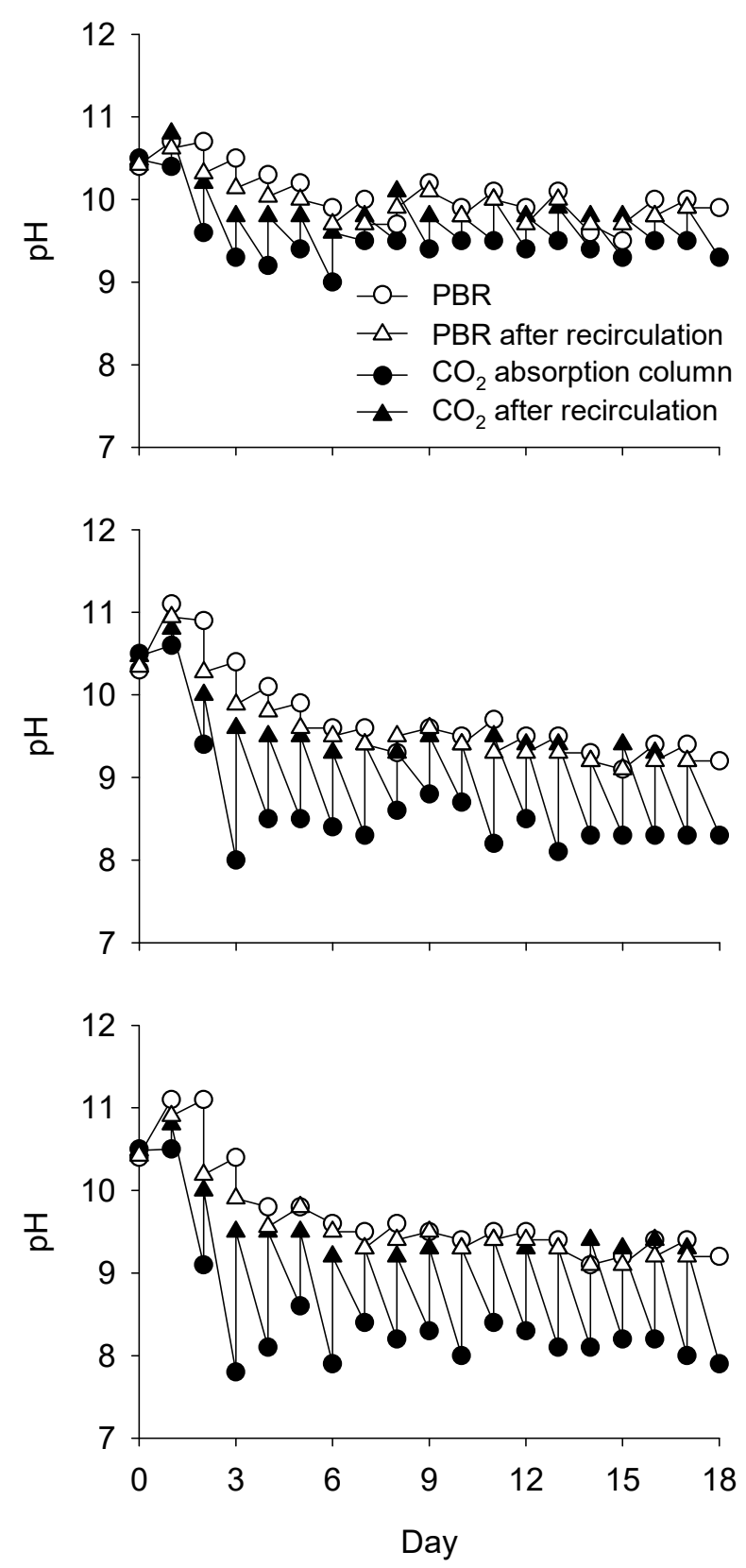

Figure 2. Time course of $\mathrm{pH}$ of each reactor (photobioreactors: $\mathrm{PBR}$; and $\mathrm{CO}_{2}$ absorption columns). There are two points in a day, representing $\mathrm{pH}$ change due to the circulation of medium between PBR and absorption column.

Table 2. Average $\mathrm{CO}_{2}$ fixing rate and $\mathrm{pH}$ before and after $\mathrm{CO}_{2}$ supply in absorption columns ${ }^{\mathrm{a}}$.

\begin{tabular}{|c|c|c|c|c|c|}
\hline \multirow[t]{2}{*}{ Run } & $\mathrm{CO}_{2}$ Supply Rate & $\begin{array}{c}\mathrm{CO}_{2} \text { Recovery } \\
\text { Rate, } R_{\mathrm{CO} 2}\end{array}$ & $\begin{array}{c}\mathrm{CO}_{2} \text { Removal } \\
\text { Efficiency }\end{array}$ & \multirow{2}{*}{$\begin{array}{c}\text { pH before } \mathrm{CO}_{2} \\
\text { Supply }\end{array}$} & \multirow{2}{*}{$\begin{array}{c}\text { pH after } \mathrm{CO}_{2} \\
\text { Supply }\end{array}$} \\
\hline & $\left(\mathrm{gC}\right.$ L-PBR $\left.{ }^{-1} \mathrm{~d}^{-1}\right)$ & $\left(\mathrm{gC} \mathrm{L}^{-} \mathrm{PBR}^{-1} \mathrm{~d}^{-1}\right)$ & $(\%)$ & & \\
\hline 1 & 0.20 & $0.227 \pm 0.052$ & $115^{b}$ & $9.85 \pm 0.08$ & $9.43 \pm 0.09$ \\
\hline 2 & 0.39 & $0.369 \pm 0.058$ & 94 & $9.35 \pm 0.11$ & $8.33 \pm 0.17$ \\
\hline 3 & 0.59 & $0.369 \pm 0.055$ & 63 & $9.34 \pm 0.05$ & $8.13 \pm 0.16$ \\
\hline
\end{tabular}

${ }^{a}$ Values from steady-state (Day 10-18) were averaged. ${ }^{\mathrm{b}}$ The value includes $\mathrm{CO}_{2}$ from headspace replacement. 
To elucidate the $\mathrm{pH}$ buffer characteristics of the modified SOT medium, the relationship between $\mathrm{CO}_{2}$ absorption and medium $\mathrm{pH}$ was modeled using Equation (4). The modeled curve showed a close similarity to the experimental data (Figure 3a). The accuracy was confirmed with regression, in which $\mathrm{R}^{2}$ was 0.8593 and residual mean square error (RSME) was 0.307 with an average $\mathrm{pH} 9.29$, indicating nearly $97 \%$ accuracy.
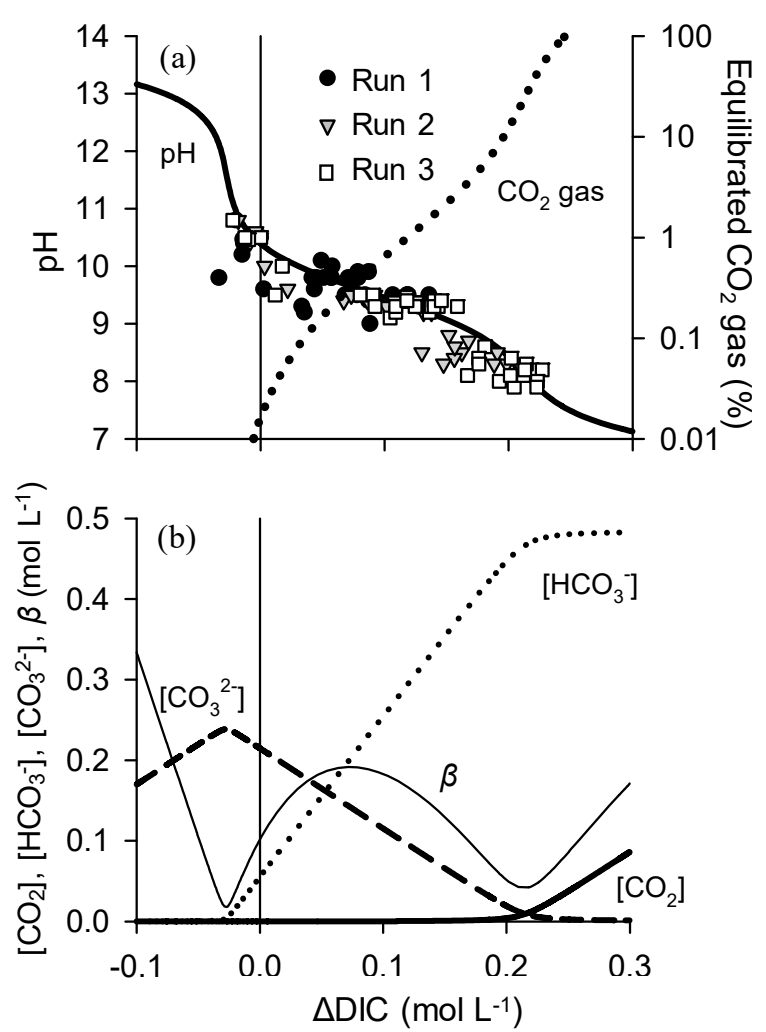

Figure 3. Estimation of (a) $\mathrm{pH}$, (b) inorganic carbon species, and buffer capacity $\beta$, from change in dissolved inorganic carbon $(\triangle \mathrm{DIC})$. All data points were from absorption columns. $\triangle \mathrm{DIC}$ was calculated by subtracting the initial dissolved inorganic carbon (DIC) (ca. $0.27 \mathrm{~mol} \mathrm{~L}^{-1}$ ) from respective DIC on each day.

Increase in $\triangle D I C\left(\mathrm{CO}_{2}\right.$ absorption) lowered the $\mathrm{pH}$ of the solution, but a buffer region existed where $\triangle D I C$ was $0-0.17 \mathrm{~mol} \mathrm{~L}^{-1}$ ( $\mathrm{pH}$ range: $8.9-10.4$; Figure 3a), at which buffer intensity $\beta$ was over half the maximum ( $>0.10 \mathrm{~mol} \mathrm{~L}^{-1}$; Figure 3b). In Runs 2 and 3 after Day 3, the $\mathrm{CO}_{2}$ absorbent received so large amount of $\mathrm{CO}_{2}$ gas that $\triangle D I C$ exceeded the buffer region, causing drastic drops of $\mathrm{pH}$ down to approximately 8.5 (Figure 2). Although the DIC in the PBR increased with a longer experimental duration in all conditions, the maximum value was $0.43 \mathrm{~mol} \mathrm{~L}^{-1}\left(\triangle D I C=0.16 \mathrm{~mol} \mathrm{~L}^{-1}\right)$ in Run 3, which was within the buffer region $\left(0-0.17 \mathrm{~mol} \mathrm{~L}^{-1}\right)$. As a result, the $\mathrm{pH}$ in PBR remained over 9 even in Runs 2 and 3 (Figure 2). Equilibrated $\mathrm{CO}_{2}$ gas concentration was also drawn in Figure 3a based on Equation (6). With a slight increase in $\triangle D I C$ less than $0.02 \mathrm{~mol} \mathrm{~L}^{-1}$, equilibrated $\mathrm{CO}_{2}$ gas exceeded atmospheric concentration (c.a. $0.04 \%$ ).

\subsection{Algal Growth and DOC Excretion}

The biomass concentrations of $A$. platensis in PBRs showed similar trends among three Runs; it increased until Day 8-11 and became steady-state (Figure 4a). The average steady-state biomass concentrations were $1.33 \pm 0.07,1.42 \pm 0.08$, and $1.34 \pm 0.10 \mathrm{gDW} \mathrm{L}^{-1}$ for Runs 1,2 , and 3, respectively, and there was no statistical difference $(p>0.05)$. There was also no statistical difference in the average biomass production rates, $P_{x}$, among Runs during the steady-state $(0.27 \pm 0.10,0.31 \pm 0.10$, and 
$0.27 \pm 0.09 \mathrm{gDW} \mathrm{L}^{-1} \mathrm{~d}^{-1}$ for Runs 1, 2, and 3, respectively). Nitrate and phosphate concentrations gradually decreased during the 18 days of culture, but more than 60 and $70 \%$ of the original medium remained at the end, respectively. Dissolved organic carbon concentration kept increasing in PBRs (Figure $4 \mathrm{~b}$ ). The final concentration ranged from 260 to $367 \mathrm{mgC} \mathrm{L}^{-1}$, while all Runs had similar initial values (110-128 $\left.\mathrm{mgC} \mathrm{L}^{-1}\right)$.

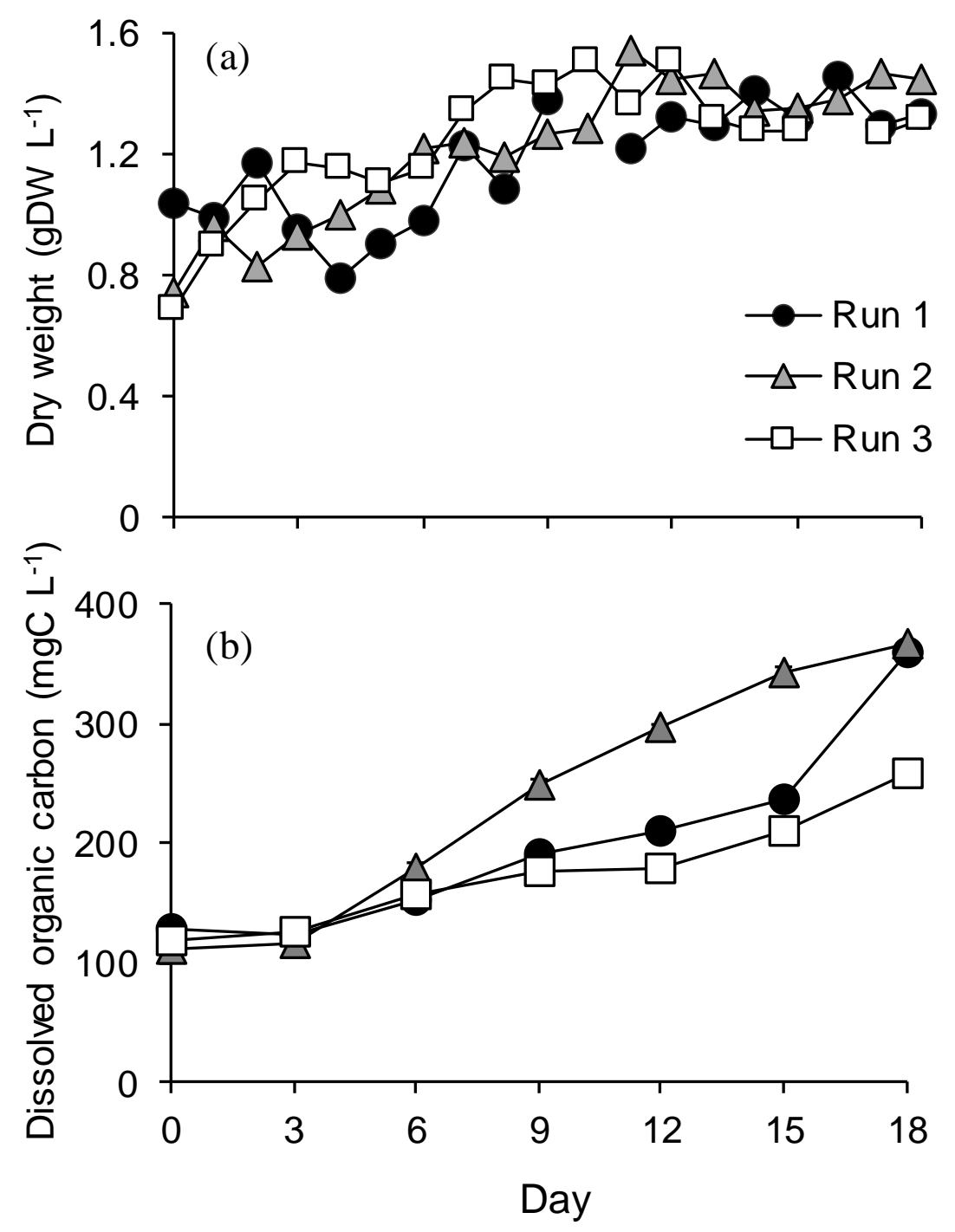

Figure 4. Photosynthesis-based products in the photobioreactors: (a) algal growth and (b) dissolved organic carbon.

\subsection{Carbon Mass Balance}

The carbon content of the dry cell of $A$. platensis during this experiment was found to be $32 \pm 4 \%$ from the elemental analysis, and it did not change significantly throughout the experiment. The overall balance between the total incoming carbon mass $\left(\mathrm{C}_{i n}\right.$; absorbed + remained $\left.\mathrm{CO}_{2}\right)$ and outgoing carbon mass $\left(C_{\text {out }}\right.$; differences between initial and final concentrations of DIC, DOC, and POC) was evaluated (Figure 5). Near closure of the balance was observed with the difference of less than 3-23\% between $\mathrm{C}_{\text {in }}$ and $\mathrm{C}_{\text {out }}$. The absorbed $\mathrm{CO}_{2}$ was converted into DIC, DOC, and POC. Average biological carbon fixation (DOC + POC) rates were $0.114,0.131$, and $0.103 \mathrm{gC} \mathrm{L}^{-1} \mathrm{~d}^{-1}$ for Runs 1,2 , and 3, respectively, and the conversion efficiencies from absorbed $\mathrm{CO}_{2}$ to DOC + POC were 58, 38, and 30\%, respectively. The difference between $\mathrm{CO}_{2}$ supply and biological carbon fixation was relatively large in Runs 2 and 3 , causing DIC accumulation (Figures S3 and S4) and pH decrease in the absorption column (Figure 2). 
The carbon mass flux analysis also revealed that out of all photosynthetically fixed carbon (increased and discharged POC + DOC), 16-24\% was converted into DOC (Figure 5). The accumulated DIC ultimately escaped from the system in the medium discharge (cf. supplementary data Figure S5 for carbon flux).

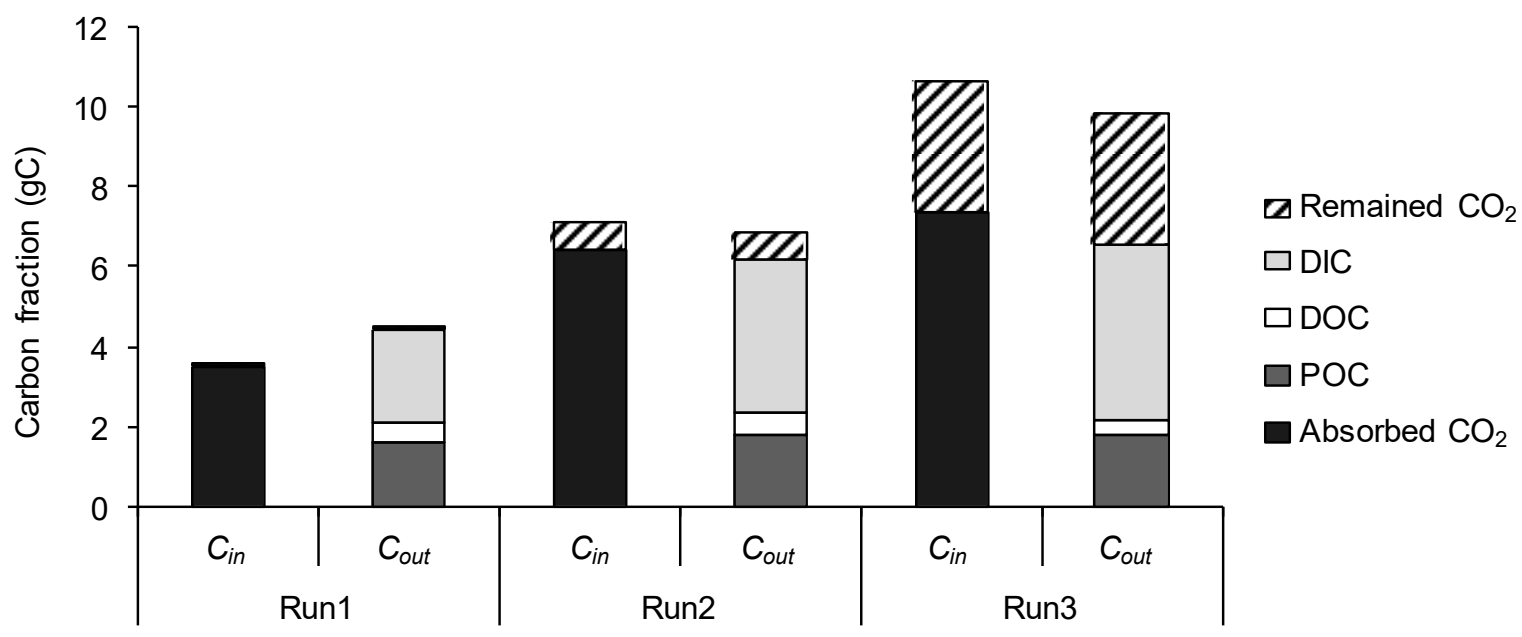

Figure 5. Carbon mass balance analysis of the experiments with $\mathrm{CO}_{2}$ supply rate of Run 1 (16 mmol

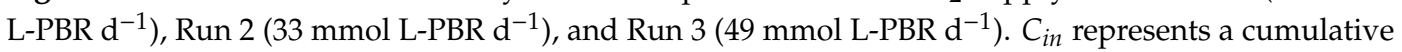
$\mathrm{CO}_{2}$ supply. $\mathrm{C}_{\text {out }}$ mainly consisted of algal biomass (particulate organic carbon; POC), dissolved inorganic carbon (DIC) and dissolved organic carbon (DOC) in the medium. Remained $\mathrm{CO}_{2}$ refers to the unabsorbed gas in the absorption columns.

\section{Discussion}

\subsection{Effect of High $\mathrm{CO}_{2}$ Supply}

According to the carbon mass balance analysis, the $\mathrm{CO}_{2}$ supply was found to be higher than carbon assimilation by Arthrospira in all conditions (Figure 5). Nonetheless, the strong $\mathrm{pH}$ buffer contained in alkaliphilic algal media allowed stable $\mathrm{pH}$ even with high $\mathrm{CO}_{2}$ supply, and nearly $100 \%$ $\mathrm{CO}_{2}$ recoveries were achieved for Runs 1 and 2 (Table 2). These results indicate the stability of the $\mathrm{CO}_{2}$ recovery process using alkaliphilic algae culture. The highest $\mathrm{CO}_{2}$ supply (Run 3) resulted in lower $\mathrm{CO}_{2}$ recovery $(63 \%)$ due to increased $\left[\mathrm{CO}_{2}\right]$. Absorption of $\mathrm{CO}_{2}$ led to a reduction of $\mathrm{pH}$ and an increase in DIC, both resulting in increased $\left[\mathrm{CO}_{2}\right]$. When $\left[\mathrm{CO}_{2}\right]$ reached a high level that equilibrated with gas $\mathrm{CO}_{2}$ concentration, the $\mathrm{CO}_{2}$ absorption terminated. Similar results were obtained in previous studies that tested $\mathrm{CO}_{2}$ absorption with high-DIC medium [21,22]. Gonzalez-Lopez et al. [22] tested various concentrations of $\mathrm{NaHCO}_{3}$ and $\mathrm{Na}_{2} \mathrm{CO}_{3}$ for $\mathrm{CO}_{2}$ recovery. Without the addition of alkaline agents, $\mathrm{pH}$ reduced from 10 to less than 7 in the first $2 \mathrm{~min}$. On the other hand, $>0.3 \mathrm{~mol} \mathrm{~L}^{-1}$ of $\mathrm{NaHCO}_{3}$ and $\mathrm{Na}_{2} \mathrm{CO}_{3}$ sustained $\mathrm{pH}>9.5$ for more than $30 \mathrm{~min}$, resulting in total carbon absorption of up to $2.0 \mathrm{~g} \mathrm{~L}^{-1}$. Total absorptivity increased with increasing initial DIC. As such, estimation of the maximal $\mathrm{CO}_{2}$ absorptivity of the target medium should be necessary for designing an efficient $\mathrm{CO}_{2}$ recovery system. See Supplementary Material Sections S2 and S3 for the estimation of maximal $\mathrm{CO}_{2}$ absorptivity of the current experiment.

The effect of high $\mathrm{CO}_{2}$ supply rates on Arthrospira growth was minimized because of the separation of the $\mathrm{CO}_{2}$ absorption column and the PBR, as suggested in previous studies $[10,21,22]$. While $\mathrm{pH}$ was reduced to less than 8.5 in the $\mathrm{CO}_{2}$ absorption column of Runs 2 and 3, it was maintained at around 9.5 in PBRs (Figure 3). Since $\mathrm{CO}_{2}$ absorption reached oversaturation in the absorption column of Run 3 , further $\mathrm{CO}_{2}$ absorption was prevented, which worked as a protection to avoid excess carbon supply for Arthrospira growth. Since the optimum pH of Arthrospira is 9.8, and its $20 \%$ growth reduction is estimated at $\mathrm{pH}<9.2$ [17], such protection worked effectively to prevent growth reduction. 
Carbon mass balance suggested a negligible escape of DIC from PBRs to the atmosphere as gaseous $\mathrm{CO}_{2}$, although $\left[\mathrm{CO}_{2}\right]$ was higher than air-equilibrium level (Figure 3a; cf. Section 3.1). This contradictory result could be explained by the prevention of air exchange between PBR headspace and atmosphere owing to the air-vent filters attached to the PBRs. In practical operations, Arthrospira cultures are majorly conducted in an outdoor pond or in an aerated PBR. To prevent DIC escapes in such conditions, $\mathrm{CO}_{2}$ supply should be adjusted to maintain $\triangle D I C$ close to the air-equilibrium (in the current condition, $\triangle D I C<0.02 \mathrm{~mol} \mathrm{~L}^{-1}$ ). Such $\triangle D I C$ level is also preferential for Arthrospira culture, since $\mathrm{pH}<9.5$ reportedly would increase the risk of contamination [2].

\subsection{Effect of Medium Recycling}

In the current process, $75 \%$ of the harvested medium was recycled (Figure 1). According to Cui et al. [24], the cost of alkaline agent reaches $91 \%$ of the total medium cost. The current medium recycling process saved $68 \%$ of the medium cost, under the assumption that other nutrients are supplemented at every recycling. The medium cost can be further reduced if the medium recycling rate and nutrient supplementation are optimized.

With high $\mathrm{CO}_{2}$ supply and medium recycling, accumulation of DIC and DOC were observed in all Runs (Figures 2 and 3). Previous studies reported reduced growth rate with high DIC $\left(>0.3 \mathrm{~mol} \mathrm{~L}^{-1}\right.$; [17]) and DOC (>60-100 $\left.\mathrm{mg} \mathrm{L}^{-1} ;[8,29]\right)$. However, in this study, no significant reduction in biomass production rate or in growth rate was observed. The DIC accumulation seemingly did not have much effect at the current level (up to $0.4 \mathrm{~mol} \mathrm{~L}^{-1}$ ). On the other hand, DOC concentration was 2-3 times higher than the reported inhibition level. The reason this DOC did not show clear inhibition could be the difference in DOC characteristics. A previous study with a green alga Scenedesmus acuminatus reported differential inhibitive levels of DOC depending on growth stages, where DOC from the declining phase had severer inhibition than that from exponential and stationary phases [30]. Differential DOC inhibition levels were also observed between the indoor and outdoor culture of Arthrospira, where DOC in indoor culture inhibited the growth at as low DOC as $65 \mathrm{mg} \mathrm{L}^{-1}$, while that in outdoor culture did not significantly inhibit the growth even at $900 \mathrm{mg} \mathrm{L}^{-1}$ [24]. Since the current semi-continuous culture maintained continuous growth, cells may not have excreted inhibitive DOC. Further study is needed to elucidate the effect of high $\mathrm{CO}_{2}$ supply on the characteristics of DOC.

Nevertheless, further DOC accumulation may cause contamination of heterotrophic microorganisms and growth inhibition, and therefore should be avoided. The previous study reports differential amounts of DOC excretion depending on culture conditions. In a culture of $A$. platensis, DOC release was the most substantial during stationary-phase ( $>30 \%$ primary production), but it was below 5\% during the exponential phase [31]. Excretion of DOC could be decreased through raising the culture-specific growth rate, by maintaining actively growing cells. Since the specific growth rate can be controlled by adjusting the dilution rate [32], a high dilution rate of the PBR may help to keep cells active for minimized DOC production. The excretion of DOC also changes with nutrient availability [33,34], mechanical mixing, and so on. Further study is necessary to elucidate the effect of those conditions on the production and inhibitive characteristics of DOC.

\subsection{Evaluation of $\mathrm{CO}_{2}$ Recovery with Media-Recycled Arthrospira Culture}

The large $\mathrm{CO}_{2}$ absorption capacity of the high-DIC medium is an advantage of the current $\mathrm{CO}_{2}$ recovery process. The large capacity enables $\mathrm{pH}$ stability. For example, the $\mathrm{pH}$ of the absorbent only decreased from 10.5 to 7.9 with continued $\mathrm{CO}_{2}$ supply (total absorption of $2.6 \mathrm{gC} \mathrm{L}^{-1}$ ), while it would decrease from 10.5 to 5.2 with merely $0.06 \mathrm{gC} \mathrm{L}^{-1}$ of $\mathrm{CO}_{2}$ without buffer. The $\mathrm{pH}$ reduction limits not only $\mathrm{CO}_{2}$ absorption but also the growth of algae. Most algae have narrow ranges of suitable pHs, such as 9-10.5 for Arthrospira platensis [17], 7-8 for Dunaliella salina [35], and 6-8 for Chlorella sorokiniana [36], and an abrupt $\mathrm{pH}$ change may severely hinder the growth. The $\mathrm{pH}$ buffer is especially important with an outdoor algae culture, since algal $\mathrm{CO}_{2}$ fixation fluctuates depending on the weather and seasons. When algal $\mathrm{CO}_{2}$ fixation is low, $\mathrm{CO}_{2}$ supply may lead to a drastic drop in $\mathrm{pH}$ without 
buffer functions. Therefore, $\mathrm{CO}_{2}$ recovery using Arthrospira culture may be incorporated into the outdoor culture, which would decrease the cost and energy input in $\mathrm{CO}_{2}$ recovery and algae production.

A similar $\mathrm{CO}_{2}$ recovery with media-recycled Arthrospira culture was attempted by Cui et al. [24]. They achieved a $\mathrm{CO}_{2}$ fixation rate of $0.31 \mathrm{gCO}_{2} \mathrm{~L}^{-1} \mathrm{~d}^{-1}$, which was similar to $0.32-0.36 \mathrm{gCO}_{2} \mathrm{~L}^{-1} \mathrm{~d}^{-1}$ of this study. They revealed a correlation of growth deterioration and DOC accumulation after repeated medium recycle, which was not observed in the current experiment probably owing to the difference in the culture mode (batch or semi-continuous) and/or duration (26 days or 18 days). Another study was performed by Gonzalez-Lopez et al. [22] on $\mathrm{CO}_{2}$ recovery with an alkaliphilic cyanobacterium Anabaena sp. They achieved nearly $100 \% \mathrm{CO}_{2}$ recovery and productivity of up to $0.4 \mathrm{~g} \mathrm{~L}^{-1} \mathrm{~d}^{-1}$, which were similar to the current study. They were successful in predicting kinetic reactions of $\mathrm{CO}_{2}$ recovery using a model. However, neither study reported the carbon mass balance and the fate of carbon incorporated into the system. The fate of carbon may change the interpretation of recovery efficiency. For example, Gonzalez-Lopez et al. [22] reported $95 \%$ efficiency of carbon utilization as to explain only about $4 \%$ escaped as $\mathrm{CO}_{2}$ gas, but this efficiency does not take into account the remaining DIC and excreted DOC as unused or unnecessary carbon output. The current study revealed that $24 \%$ of assimilated carbon was released as $\mathrm{CO}_{2}$ (Figure 5). If this DOC requires further treatment, such as aerobic activated sludge, the carbon footprint would be higher than previously reported algal CCU process. Thus, this study indicated the importance of carbon mass balance analysis in the practical evaluation of $\mathrm{CO}_{2}$ recovery processes.

\section{Conclusions}

This study conducted semi-continuous cultures of A. platensis with medium recycling and $\mathrm{CO}_{2}$ supply. Medium recycling enabled $68 \%$ of total medium cost reduction and did not affect the algal growth although DIC and DOC accumulated in the medium. Carbon dioxide recovery rates of $63-100 \%$ and steady algal growth of $0.31 \mathrm{gDW} \mathrm{L}^{-1} \mathrm{~d}^{-1}$ were achieved even with the excessive carbon supply compared with the $A$. platensis carbon assimilation. Carbon mass balance analysis revealed that up to $24 \%$ of the assimilated carbon escapes into the medium in a form of DOC, and thus care needs to be taken in evaluating the process. This study demonstrated the effectiveness and stability of the medium-recycling process even at high $\mathrm{CO}_{2}$ supply rates. Further study is needed to elucidate the mechanisms of DOC excretion and its effects on the growth and biomass characteristics.

Supplementary Materials: The following are available online at http://www.mdpi.com/2076-3417/10/1/228/s1: explanations on Figure S1. Modified SOT medium titration with $\mathrm{KOH}(2) \mathrm{CO}_{2}$ partial pressure in the absorption columns, Figure S2. Calculated and experimental amount of the absorbed $\mathrm{CO}_{2}$ over $24 \mathrm{~h}(\mathrm{CO} 2 a b s)$ at different initial dissolved inorganic carbon (DIC). Plots: experimental values; solid lines: calculated values; and dashed lines: theoretical $100 \%$ absorption of supplied $\mathrm{CO}_{2}$ Figure S3. Dissolved inorganic carbon concentrations in $\mathrm{CO}_{2}$ absorption columns; $(\mathbf{a}, \mathbf{c}, \mathbf{e})$ after $\mathrm{CO}_{2}$ supply, and $(\mathbf{b}, \mathbf{d}, \mathbf{f})$ after medium recycle from the photobioreactors. Low $\mathrm{pH}$ after $\mathrm{CO}_{2}$ supply induced decrease of $\mathrm{CO}_{3}{ }^{2-}$ fraction and increase of $\mathrm{HCO}_{3}{ }^{-}$and $\mathrm{CO}_{2}$ fractions, Figure S4. Dissolved inorganic carbon concentration in photobioreactors; (a,c,e) after 1-day incubation, and (b,d,f) after medium input from $\mathrm{CO}_{2}$ absorption columns. Slight reduction in total DIC after incubation was observed. Figure S5. Carbon mass flux during 18-day operation. $\mathrm{CO}_{2}$ supply rate of (a) Run 1, (b) Run 2, and (c) Run 3 . Each box represents total cumulative mass (in milligram) of carbon fraction introduced or discharged over 18 days in the forms of $\mathrm{CO}_{2}$, dissolved inorganic carbon (DIC), dissolved organic carbon (DOC) or algal biomass (particulate organic carbon; POC). The mass inside the $\mathrm{CO}_{2}$ absorption column and photobioreactor represent differences from the initial state.

Author Contributions: Conceptualization, M.K. and T.T.; methodology, M.K., Y.Y., and T.K.; software, T.M.; formal analysis, M.K. and T.M.; investigation, M.K. and Y.Y.; writing-Original draft preparation, M.K.; writing-Review and editing, T.K., T.M., and T.T; supervision, T.T.; funding acquisition, T.T. All authors have read and agreed to the published version of the manuscript.

Funding: This study was partially supported by Japan Science and Technology Agency (JST)/Japan International Cooperation Agency (JICA), Science and Technology Research Partnership for Sustainable Development (SATREPS) and PLANE3T Project funded by the Private University Research Branding Project supported by Japanese Ministry of Education, Culture, Sports, Science and Technology (MEXT).

Conflicts of Interest: The authors declare no conflict of interest. 


\section{References}

1. Furmaniak, M.A.; Misztak, A.E.; Franczuk, M.D.; Wilmotte, A.; Waleron, M.; Waleron, K.F. Edible cyanobacterial genus Arthrospira: Actual state of the art in cultivation methods, genetics, and application in medicine. Front. Microbiol. 2017, 8, 1-21. [CrossRef] [PubMed]

2. Belay, A. Biology and industrial production of Arthrospira (Spirulina). In Handbook of Microalgal Culture: Applied Phycology and Biotechnology; Richmond, A., Hu, Q., Eds.; John Wiley \& Sons, Ltd.: Oxford, UK, 2013; pp. 339-358. ISBN 9780470673898.

3. Kurd, F.; Samavati, V. Water soluble polysaccharides from Spirulina platensis: Extraction and in vitro anti-cancer activity. Int. J. Biol. Macromol. 2015, 74, 498-506. [CrossRef] [PubMed]

4. Agustini, T.W.; Suzery, M.; Sutrisnanto, D.; Ma'ruf, W.F. Hadiyanto Comparative study of bioactive substances extracted from fresh and dried Spirulina sp. Procedia Environ. Sci. 2015, 23, 282-289. [CrossRef]

5. Choi, W.Y.; Sim, J.-H.; Lee, J.-Y.; Kang, D.H.; Lee, H.Y. Increased anti-inflammatory effects on LPS-induced microglia cells by Spirulina maxima extract from ultrasonic process. Appl. Sci. 2019, 9, 2144. [CrossRef]

6. Choi, W.; Kang, D.; Heo, S.-J.; Lee, H. Enhancement of the neuroprotective effect of fermented Spirulina maxima associated with antioxidant activities by ultrasonic extraction. Appl. Sci. 2018, 8, 2469. [CrossRef]

7. Zarrouk, C. Contribution à L'étude D'une Cyanophycée: Influence de Divers Facteurs Physiques et Chimiques sur la Croissance et la Photosynthèse de Spirulina maxima (Setch et Gardner) Geitler. Ph.D. Thesis, University of Paris, Paris, France, 1966.

8. Depraetere, O.; Pierre, G.; Noppe, W.; Vandamme, D.; Foubert, I.; Michaud, P.; Muylaert, K. Influence of culture medium recycling on the performance of Arthrospira platensis cultures. Algal Res. 2015, 10, 48-54. [CrossRef]

9. Mejia-da-Silva, L.d.C.; Matsudo, M.C.; Morocho-Jacome, A.L.; de Carvalho, J.C.M. Application of physicochemical treatment allows reutilization of Arthrospira platensis exhausted medium: An investigation of reusing medium in Arthrospira platensis cultivation. Appl. Biochem. Biotechnol. 2018, 186, 40-53. [CrossRef]

10. Chi, Z.; O'Fallon, J.V.; Chen, S. Bicarbonate produced from carbon capture for algae culture. Trends Biotechnol. 2011, 29, 537-541. [CrossRef]

11. Arroyo, C.A.; Contreras, J.L.; Zeifert, B.; Ramírez, C. $\mathrm{CO}_{2}$ capture of the gas emission, using a catalytic converter and airlift bioreactors with the microalga Scenedesmus dimorphus. Appl. Sci. 2019, 9, 3212. [CrossRef]

12. Kumar, K.; Dasgupta, C.N.; Nayak, B.; Lindblad, P.; Das, D. Development of suitable photobioreactors for $\mathrm{CO}_{2}$ sequestration addressing global warming using green algae and cyanobacteria. Bioresour. Technol. 2011, 102, 4945-4953. [CrossRef]

13. Singh, J.; Dhar, D.W. Overview of carbon capture technology: Microalgal biorefinery concept and state-of-the-art. Front. Mar. Sci. 2019, 6, 1-9. [CrossRef]

14. Cuéllar-Franca, R.M.; Azapagic, A. Carbon capture, storage and utilisation technologies: A critical analysis and comparison of their life cycle environmental impacts. J. $\mathrm{CO}_{2}$ Util. 2015, 9, 82-102. [CrossRef]

15. Klamczynska, B.; Mooney, W.D. Heterotrophic Microalgae. In Sustainable Protein Sources; Elsevier: Amsterdam, The Netherlands, 2017; pp. 327-339. ISBN 9780128027769.

16. Al-Mamoori, A.; Krishnamurthy, A.; Rownaghi, A.A.; Rezaei, F. Carbon Capture and Utilization Update. Energy Technol. 2017, 5, 834-849. [CrossRef]

17. Kishi, M.; Toda, T. Carbon fixation properties of three alkalihalophilic microalgal strains under high alkalinity. J. Appl. Phycol. 2017, 30, 1-10. [CrossRef]

18. Pancha, I.; Chokshi, K.; Ghosh, T.; Paliwal, C.; Maurya, R.; Mishra, S. Bicarbonate supplementation enhanced biofuel production potential as well as nutritional stress mitigation in the microalgae Scenedesmus sp. CCNM 1077. Bioresour. Technol. 2015, 193, 315-323. [CrossRef]

19. Kang, C.D.; Lee, J.S.; Park, T.H.; Sim, S.J. Comparison of heterotrophic and photoautotrophic induction on astaxanthin production by Haematococcus pluvialis. Appl. Microbiol. Biotechnol. 2005, 68, 237-241. [CrossRef]

20. Tripathi, R.; Singh, J.; Thakur, I.S. Characterization of microalga Scenedesmus sp. ISTGA1 for potential $\mathrm{CO}_{2}$ sequestration and biodiesel production. Renew. Energy 2015, 74, 774-781. [CrossRef]

21. Chi, Z.; Xie, Y.; Elloy, F.; Zheng, Y.; Hu, Y.; Chen, S. Bicarbonate-based Integrated Carbon Capture and Algae Production System with alkalihalophilic cyanobacterium. Bioresour. Technol. 2013, 133, 513-521. [CrossRef] 
22. González-López, C.V.; Acién Fernández, F.G.; Fernández-Sevilla, J.M.; Sánchez Fernández, J.F.; Molina Grima, E. Development of a process for efficient use of $\mathrm{CO}_{2}$ from flue gases in the production of photosynthetic microorganisms. Biotechnol. Bioeng. 2012, 109, 1637-1650. [CrossRef]

23. Canon-Rubio, K.A.; Sharp, C.E.; Bergerson, J.; Strous, M.; De la Hoz Siegler, H. Use of highly alkaline conditions to improve cost-effectiveness of algal biotechnology. Appl. Microbiol. Biotechnol. 2016, 100, 1611-1622. [CrossRef]

24. Cui, H.; Yang, Z.; Lu, Z.; Wang, Q.; Liu, J.; Song, L. Combination of utilization of $\mathrm{CO}_{2}$ from flue gas of biomass power plant and medium recycling to enhance cost-effective Spirulina production. J. Appl. Phycol. 2019, 31, 2175-2185. [CrossRef]

25. Ogawa, T.; Terui, G. Studies on the growth of Spirulina platensis: (I) On the pure culture of Spirulina platensis. J. Ferment. Technol. 1970, 48, 361-367.

26. Zeebe, R.; Wolf-Gladrow, D. $\mathrm{CO}_{2}$ in Seawater-Equilibrium, Kinetics, Isotopes, 1st ed.; Halpern, D., Ed.; Elsevier: Amsterdam, The Netherlands, 2001; ISBN 978-0-444-50946-8.

27. Camacho Rubio, F.; Acién Fernández, F.G.; Sánchez Pérez, J.A.; García Camacho, F.; Molina Grima, E. Prediction of dissolved oxygen and carbon dioxide concentration profiles in tubular photobioreactors for microalgal culture. Biotechnol. Bioeng. 1999, 62, 71-86. [CrossRef]

28. Stumm, W.; Morgan, J.J. Aquatic Chemistry: Chemical Equilibria and Rates in Natural Waters, 3rd ed.; Wiley-Interscience: New York, NY, USA, 1993; Volume 3, ISBN 0471511854.

29. Zengling, M.; Kunshan, G.; Teruo, W. Effects of dissolved organic matter on the growth and pigments synthesis of Spirulina platensis (Arthospira). Prog. Nat. Sci. 2006, 16, 50-54. [CrossRef]

30. Sha, J.; Lu, Z.; Ye, J.; Wang, G.; Hu, Q.; Chen, Y.; Zhang, X. The inhibition effect of recycled Scenedesmus acuminatus culture media: Influence of growth phase, inhibitor identification and removal. Algal Res. 2019, 42, 101612. [CrossRef]

31. Gordillo, F.J.L.; Jiménez, C.; Figueroa, F.L.; Niell, F.X. Effects of increased atmospheric $\mathrm{CO}_{2}$ and $\mathrm{N}$ supply on photosynthesis, growth and cell composition of the cyanobacterium Spirulina platensis (Arthrospira). J. Appl. Phycol. 1998, 10, 461-469. [CrossRef]

32. Lee, Y.-K.; Chen, W.; Shen, H.; Han, D.; Li, Y.; Jones, H.D.T.; Timlin, J.A.; Hu, Q. Basic culturing and analytical measurement techniques. In Handbook of Microalgal Culture: Applied Phycology and Biotechnology; Richmond, A., Hu, Q., Eds.; John Wiley \& Sons, Ltd.: Oxford, UK, 2013; pp. 37-68. ISBN 9781118567166.

33. Wang, M.; Kuo-Dahab, W.C.; Dolan, S.; Park, C. Kinetics of nutrient removal and expression of extracellular polymeric substances of the microalgae, Chlorella sp. and Micractinium sp., in wastewater treatment. Bioresour. Technol. 2014, 154, 131-137. [CrossRef]

34. Zhao, L.; Lu, L.; Li, M.; Xu, Z.; Zhu, W. Effects of Ca and Mg levels on colony formation and EPS content of cultured M. aeruginosa. Procedia Environ. Sci. 2011, 10, 1452-1458. [CrossRef]

35. Subba Rao, D. Cultivation, growth media, division rates and applications of Dunaliella species. In The Alga Dunaliella; Ben-Amotz, A., Polle, J.E.W., Subba Rao, D.V., Eds.; Science Publishers: Enfield, NH, USA, 2009; pp. 45-89. ISBN 9781578085453.

36. Zheng, Y.; Li, T.; Yu, X.; Bates, P.D.; Dong, T.; Chen, S. High-density fed-batch culture of a thermotolerant microalga Chlorella sorokiniana for biofuel production. Appl. Energy 2013, 108, 281-287. [CrossRef]

(C) 2019 by the authors. Licensee MDPI, Basel, Switzerland. This article is an open access article distributed under the terms and conditions of the Creative Commons Attribution (CC BY) license (http://creativecommons.org/licenses/by/4.0/). 